\title{
Quantitative analysis of mitochondrial DNAs in macaque embryos reprogrammed by rabbit oocytes
}

\author{
Cai-Xia Yang, Zhao-Hui Kou, Kai Wang ${ }^{1}$, Yan Jiang, Wen-Wei Mao ${ }^{1}$, Qing-Yuan Sun, \\ Hui-Zhen Sheng ${ }^{1}$ and Da-Yuan Chen
}

State Key Laboratory of Reproductive Biology, Institute of Zoology, Chinese Academy of Sciences, 25 Bei Si Huan Xi Lu, Haidian, Beijing 100080, China and ${ }^{1}$ Center for Developmental Biology,

Shanghai Second Medical University/Laboratory of Stem Cell Biology, Institute of Biochemistry and Cell Biology, Chinese Academy of Sciences, 1665 Kong Jiang Road, Shanghai 200092, China

Correspondence should be addressed to D-Y Chen; Email: chendy@panda.ioz.ac.cn

\begin{abstract}
In cloned animals where somatic cell nuclei and oocytes are from the same or closely related species, the mitochondrial DNA (mtDNA) of the oocyte is dominantly inherited. However, in nuclear transfer (NT) embryos where nuclear donor and oocyte are from two distantly related species, the distribution of the mtDNA species is not known. Here we determined the levels of macaque and rabbit mtDNAs in macaque embryos reprogrammed by rabbit oocytes. Quantification using a realtime PCR method showed that both macaque and rabbit mtDNAs coexist in NT embryos at all preimplantation stages, with maternal mtDNA being dominant. Single NT embryos at the 1-cell stage immediately after fusion contained $2.6 \times 10^{4}$ copies of macaque mtDNA and $1.3 \times 10^{6}$ copies of rabbit mtDNA. Copy numbers of both mtDNA species did not change significantly from the 1-cell to the morula stages. In the single blastocyst, however, the number of rabbit mtDNA increased dramatically while macaque mtDNA decreased. The ratio of nuclear donor mtDNA to oocyte mtDNA dropped sharply from $2 \%$ at the 1 -cell stage to $0.011 \%$ at the blastocyst stage. These results suggest that maternal mtDNA replicates after the morula stage.
\end{abstract}

Reproduction (2004) 127 201-205

\section{Introduction}

Mammalian cells contain two distinct genomes; one is located in the nucleus, and the other in mitochondria (mtDNA). mtDNA is a double-stranded DNA circle of about $16-17 \mathrm{~kb}$, which encodes only 13 proteins involved in the process of oxidative phosphorylation (Smith \& Alcivar 1993). The rest of the proteins in the mitochondrial compartment are encoded by the nuclear genome. Interactions between nuclear and mitochondrial genomes are critical for the subsequent development of the embryo.

In normal mammalian fertilization, the sperm mitochondria are destroyed during preimplantation stages and the oocyte-derived mitochondria are transmitted to the offspring, so mtDNAs are inherited maternally or homoplasmically (Giles et al. 1980).

Thus far, the fate of foreign mtDNA following nuclear transfer (NT) is still controversial. In intraspecies cloned animals, mtDNA primarily arises from the oocytes (Evans et al. 1999, Takeda et al. 1999, Do et al. 2001), whereas in the others mtDNA appears to be heteroplasmic (Steinborn et al. 2000, Hiendleder et al. 1999, Do et al. 2002). In interspecies cloning where nuclear donor and oocyte are from closely related species, mtDNAs are primarily oocyte derived (Loi et al. 2001, Meirelles et al. 2001, Lanza et al. 2002). However, our previous study (Chen et al. 1999) showed that the mitochondria from donor panda cells and recipient rabbit oocytes coexist in preimplanted embryos. Similarly, heteroplasmy of mtDNA has been identified in cloned macaque-rabbit embryos by direct PCR product sequencing (Yang et al. 2003). These results indicate that mtDNA of nuclear donor origin may persist in NT embryos in interspecies NT if the nuclear donor and oocyte are from distantly related species.

In the present study, the fate of mtDNAs in preimplantation stage macaque embryos derived from interspecies cloning was quantitatively analyzed. We examined copy numbers of both macaque and rabbit mtDNAs in cloned macaque-rabbit embryos by a real-time PCR assay. 


\section{Materials and Methods}

\section{Reconstruction of macaque-rabbit cloned embryos}

Ear skin was collected from a 7-year-old female macaque (Macaca mulatta tcheliensis). Primary cell culture was performed with the same method as that described previously (Han et al. 2001). Fibroblasts at passages 4-10 were used as nuclear donors. Recipients were matured metaphase II stage (MII) rabbit oocytes flushed from oviducts with $\mathrm{M}_{2}$ medium (Sigma). Using the NT procedure described previously (Chen et al. 1999, 2002, Yang et al. 2003), MII oocytes were incubated for $10 \mathrm{~min}$ in $\mathrm{M}_{2}$ medium containing $7.5 \mu \mathrm{g} / \mathrm{ml}$ cytochalasin B (Sigma), $7.5 \mu \mathrm{g} / \mathrm{ml}$ Hoechst 33342 (Sigma) and 10\% fetal bovine serum, and then manipulated under an inverted microscope (Nikon's ECLIPSE TE300, Nikon Corporation, Japan). The first polar body with approximately one quarter to one third of the adjacent cytoplasm containing metaphase II spindle was removed. The aspirated karyoplast was exposed to u.v. light to confirm the removal of chromosomes. A single cell was then placed in the perivitelline space. The couplets were transferred into a fusion chamber overlaid with the electrical fusion solution comprising $0.25 \mathrm{M}$ sorbitol, $0.5 \mathrm{mM}$ Hepes, $0.1 \mathrm{mM} \mathrm{Ca}\left(\mathrm{CH}_{3} \mathrm{COO}\right)_{2}, 0.5 \mathrm{mM} \mathrm{Mg}\left(\mathrm{CH}_{3}\right.$ $\mathrm{COO})_{2}$ and $1 \mathrm{mg} / \mathrm{ml}$ bovine serum albumin. Cell fusion was induced with two direct current (DC) pulses $(1.2 \mathrm{kV} / \mathrm{cm}, 80 \mu \mathrm{s}$ each, $1 \mathrm{~s}$ apart). Couplets were checked for fusion under an inverted microscope, and fused couplets were activated by double DC pulses of $1.2 \mathrm{kV} / \mathrm{cm}$ for $20 \mu \mathrm{s}$, and then cultured in $\mathrm{G}_{1.2}$ medium (Vitrolife, Mölndalsvägen, Göteborg, Sweden). The 8-cell NT embryos were transferred into $\mathrm{G}_{2.2}$ medium (Vitrolife) for subsequent development.

\section{Collection of NT embryos}

NT embryos were collected directly into PCR tubes containing $10 \mu \mathrm{l}$ lysis solution, ReadyAmp genomic DNA purification resin (Promega Corporation, Madison, WI, USA) and $200 \mu \mathrm{g} / \mathrm{ml}$ added proteinase K (Sigma). The mixtures were incubated for $30 \mathrm{~min}$ at $55^{\circ} \mathrm{C}$, boiled for $10 \mathrm{~min}$, centrifuged for $1 \mathrm{~min}$, and then used as PCR templates (Wan et al. 2003).

\section{Species-specific mtDNA primers}

Sequences of macaque (GeneBank accession number U38273) and rabbit (GeneBank accession number NC001913) mtDNAs were compared with design speciesspecific primers. The macaque-specific primers were forward, 5'-CCT TCT CCT CAA TCG CAC-3' and reverse, 5'-GGA GGA GAT ATG AGC CGT AG-3'. The rabbit mtDNA specific primers were forward, 5'-CCC ATA CGA CTA TCC CTC TCC C-3' and reverse, 5'-CGT GTG GGC GAT CTT AGG TTC-3'.

\section{Standard curves}

PCR products were purified from agarose gel and inserted into pGEM-T-easy PCR cloning vector (Promega Corporation). The identities of the inserts were confirmed by sequencing. Standard curves covering $10^{6}$ to $10^{0}$ copies (with 10-fold dilutions) for macaque mtDNA and $10^{7}$ to $10^{\circ}$ copies for rabbit mtDNA were constructed (Fig. 1).

\section{Real-time PCR}

Embryos at seven preimplantation stages, including 1-cell (immediately after fusion), 2-cell, 4-cell, 8-cell, 16-cell, morula and blastocyst stages, were collected. Five embryos were analyzed for each of the seven stages. To perform assays, lysates from five embryos were mixed and used as templates. Each mixed sample was repeatedly measured three times using macaque-specific primer pairs and rabbit-specific primer pairs respectively. Unknown concentrations of samples were extrapolated by comparing with standards amplified under the same conditions using Lightcycler software 3.1 (Roche Diagnostics, Germany). The means and standard errors of triplicates were calculated and are presented in Table 1.

PCR reactions were prepared as follows: $6.4 \mu \mathrm{l}$ distilled water, $1.2 \mu \mathrm{l} \mathrm{MgCl}_{2}(25 \mathrm{mM}), 0.2 \mu \mathrm{l}$ forward primer $(20 \mu \mathrm{M}), 0.2 \mu \mathrm{l}$ reverse primer $(20 \mu \mathrm{M}), 1 \mu \mathrm{I}$ NT embryo DNA template, $1 \mu$ reagent mixture including dNTP, Taq polymerase and SYBR Green dye (Roche diagnostics, Germany). Real-time PCR assays were performed on a lightcycler (Roche diagnostics, Germany). The macaque mtDNA was amplified using the following parameters: $95^{\circ} \mathrm{C}$ for $10 \mathrm{~min}$, followed by 40 cycles at $95^{\circ} \mathrm{C}$ for $10 \mathrm{~s}$, $60^{\circ} \mathrm{C}$ for $10 \mathrm{~s}, 72^{\circ} \mathrm{C}$ for $10 \mathrm{~s}$. The rabbit mtDNA was amplified using the following parameters: $95^{\circ} \mathrm{C}$ for $10 \mathrm{~min}$, and then 40 cycles at $95^{\circ} \mathrm{C}$ for $10 \mathrm{~s}, 68^{\circ} \mathrm{C}$ for $10 \mathrm{~s}$. Each experiment included standards for macaque/rabbit mtDNAs, NT
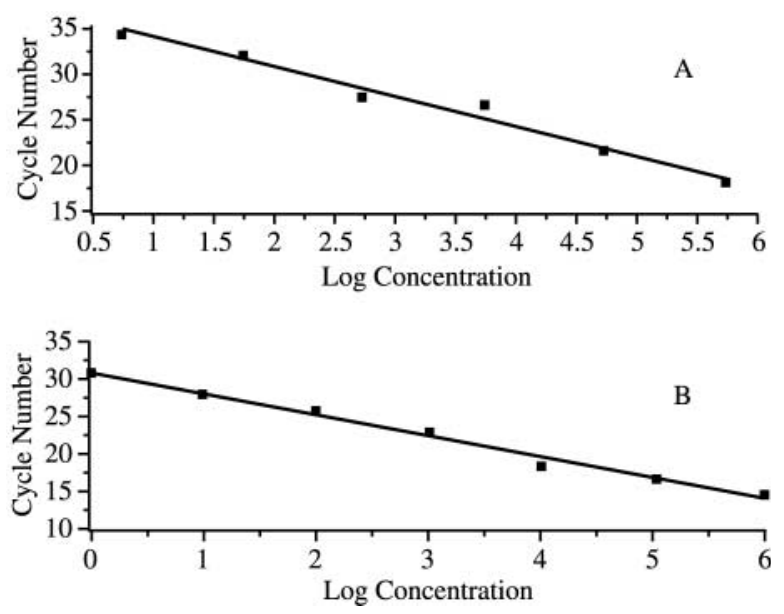

Figure 1 Regression lines of the standards from $10^{6}$ copies/ $\mu$ l to 10 copies/ $\mu \mathrm{l}$, with log copy numbers plotted on the $\mathrm{X}$ axis and the threshold cycle on the $\mathrm{Y}$ axis. (A) Macaque mtDNA standards and (B) rabbit mtDNA standards. 
Table 1 The mtDNA copy number and ratios of macaque mtDNA to rabbit mtDNA in NT embryos at different stages. Values are means of triplicates.

\begin{tabular}{lccc}
\hline & \multicolumn{2}{c}{ Copy numbers } \\
\cline { 2 - 3 } Stages & Macaque mtDNAs & Rabbit mtDNAs & Macaque mtDNA/rabbit mtDNA (\%) \\
\hline 1-cell & $2.6 \times 10^{4} \pm 1.7 \times 10^{4}$ & $1.3 \times 10^{6} \pm 0.7 \times 10^{6}$ & $2.00 \pm 0.83$ \\
2-cell & $2.8 \times 10^{4} \pm 1.8 \times 10^{4}$ & $2.1 \times 10^{6} \pm 1.3 \times 10^{6}$ & $1.33 \pm 0.57$ \\
4-cell & $2.5 \times 10^{4} \pm 2.0 \times 10^{4}$ & $1.5 \times 10^{6} \pm 1.0 \times 10^{6}$ & $1.67 \pm 1.27$ \\
8-cell & $1.0 \times 10^{4} \pm 0.8 \times 10^{4}$ & $1.6 \times 10^{6} \pm 0.9 \times 10^{6}$ & $0.63 \pm 0.34$ \\
16-cell & $2.1 \times 10^{4} \pm 1.3 \times 10^{4}$ & $2.5 \times 10^{6} \pm 1.3 \times 10^{6}$ & $0.84 \pm 0.16$ \\
Morula & $2.8 \times 10^{4} \pm 1.8 \times 10^{4}$ & $2.2 \times 10^{6} \pm 1.0 \times 10^{6}$ & $1.27 \pm 0.50$ \\
Blastocyst & $5.4 \times 10^{3} \pm 3.5 \times 10^{3}$ & $4.7 \times 10^{7} \pm 3.5 \times 10^{7}$ & $0.011 \pm 0.007$ \\
\hline
\end{tabular}

embryo, rabbit/macaque DNA controls, lysis buffer control and water control. Identities of PCR products were confirmed by their sizes in agarose gel and by sequencing.

\section{Results}

\section{Specificity of the assay}

In a cross-species test, the macaque mtDNA-specific primers detected PCR product in only macaque mtDNA but not in rabbit and human mtDNA; vice versa, the rabbit mtDNA-specific primers detected PCR products only in rabbit mtDNA but not in macaque and human mtDNA. The two primer pairs were species specific and therefore used to construct standard curves and to detect mtDNAs derived from donor cell and recipient oocyte in NT embryos at different stages.

\section{Dynamic changes of mtDNA in NT embryos}

The copies of mtDNA from donor cells and recipient oocytes in cloned embryos at 1-cell, 2-cell, 4-cell, 8-cell, 16-cell, morula and blastocyst stages were detected separately using the rabbit-specific and macaque-specific primer pairs. Results in triplicate showed that rabbit/macaque DNA controls, lysis buffer and water control were negative and the macaque/rabbit DNA standards were well proportioned (Fig. 2), and so the detected mtDNA copies were authentic. In the 1-cell stage NT embryo, the number of mtDNA copies from donor macaque somatic cells was $2.6 \times 10^{4}$, while there were $1.3 \times 10^{6} \mathrm{mtDNA}$ copies from recipient rabbit oocytes. In subsequent in vitro development of NT embryos, from the 2-cell stage to the morula stage, there were no significant changes in copy numbers of both mtDNA species. At the blastocyst stage, however, the copy number of macaque mtDNA was reduced to $5.4 \times 10^{3}$ while the copy number of rabbit mtDNA was increased to $4.7 \times 10^{7}$, bringing the ratio of macaque/rabbit mtDNAs from $2 \%$ at the 1 -cell stage to $0.011 \%$ at the blastocyst stage (Table 1 ). These results demonstrated that the mitochondria from both macaque and rabbit coexisted in these early stage NT embryos, which is consistent with our previous qualitative PCR analysis of mitochondrial fate in cloned macaque-rabbit embryos (Yang et al. 2003).

\section{Confirmation of PCR products}

PCR products from both mtDNA species were analyzed by electrophoresis and showed the expected sizes (143 bp for macaque mtDNA and $196 \mathrm{bp}$ for rabbit mtDNA). The identities of these bands were further confirmed by sequencing (data not shown).

\section{Discussion}

\section{The method for studying the mitochondrial fate in NT embryos}

During cloning manipulation by either whole-cell electrofusion or karyoplasm injection, donor nucleus with all or part of the cytoplasm is transferred into an enucleated recipient oocyte. Different cytoplasm from a donor cell and an enucleated recipient oocyte are mixed. Thus, the NT embryos should harbor two kinds of mtDNA. mtDNAs are the genetic material of mitochondria, a component of cytoplasm. In the early development of NT-reconstructed embryos, the detection of mtDNA is helpful to reveal changes of donor cytoplasm. Several methods have been used to explore the fate of mitochondria in cloning, including single-strand conformation polymorphism of PCR fragments and allele-specific PCR (AS-PCR) in cloned cattle (Takeda et al. 1999, Do et al. 2002), direct DNA sequencing in interspecies cloned panda embryos (Chen et al. 2002), DNA chromatography in cloned bovine embryos (Do et al. 2002) and restriction fragment length polymorphism in cloned sheep (Evans et al. 1999). Of these methods, AS-PCR is considered to be the most sensitive and suitable method for the analysis of mtDNA heteroplasmy. However, all these identification methods can be used to qualify the homoplasmy or heteroplasmy only, but not to quantify the number of mtDNAs. In the present study, real-time quantitative PCR was used to detect the slight changes of mtDNA in NT embryos accurately and the results demonstrated that this method can amplify $10^{1}$ copies, sometimes even $10^{\circ}$ copies, of macaque or rabbit standard (as shown in Fig. 2). Thus, this method with sensitivity to detect less than ten copies of mtDNA also can be extended to nuclear gene detection.

In order to perform real-time PCR, an effective DNA extraction protocol from a single early NT embryo should 

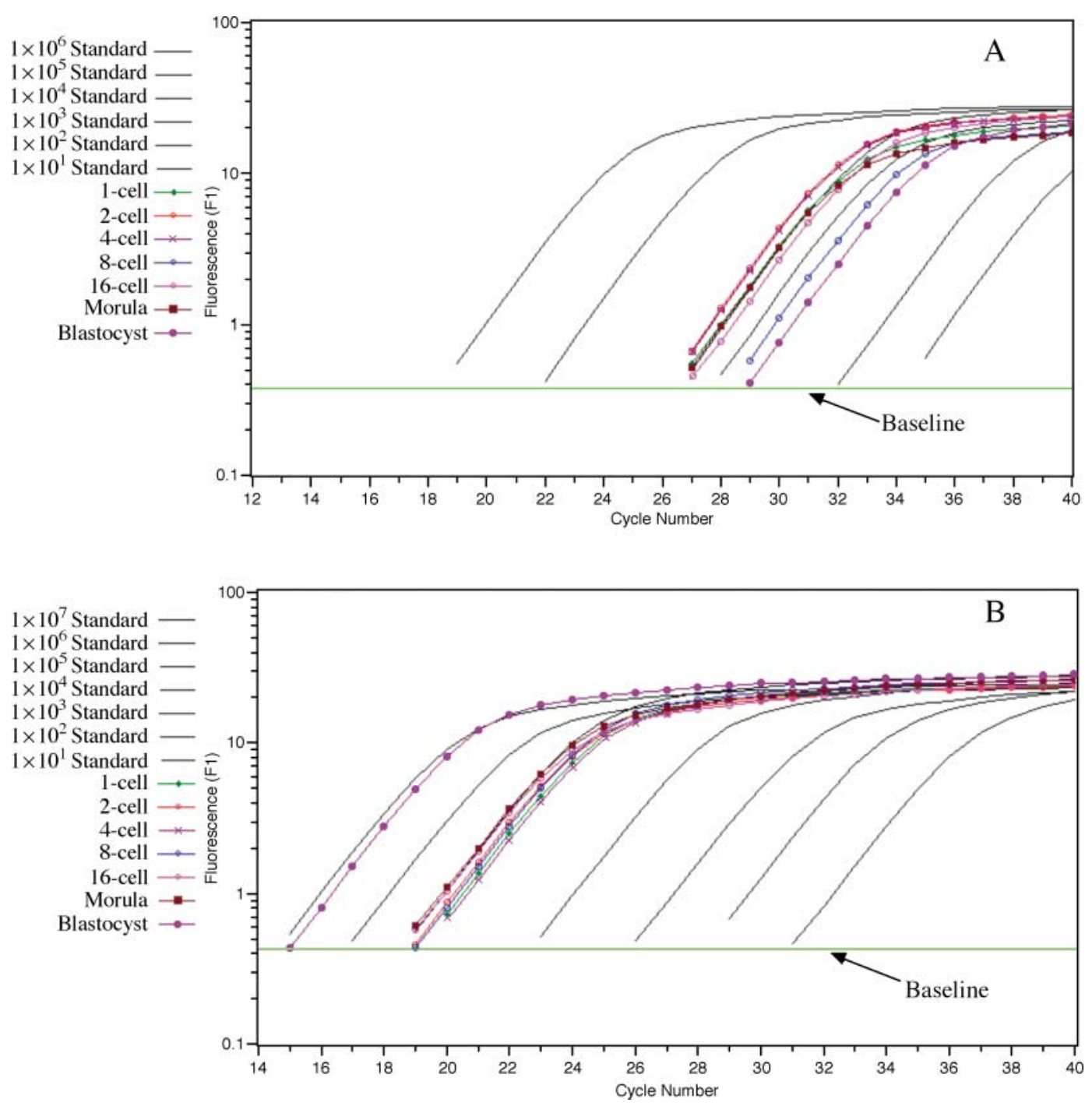

Figure 2 Analysis of mtDNA heteroplasmy. (A) and (B) show log linear phases of real-time PCR reactions of macaque and rabbit mtDNAs respectively. The Lightcycler software 3.1 extrapolates unknown concentrations from the threshold cycles of the standards.

be developed. We previously used a very simple and rapid approach described by Wan et al. (2003) for qualitative mtDNA analysis of macaque-rabbit NT embryos by direct DNA sequencing. The method of DNA extraction, by adding $100 \mu \mathrm{g} / \mathrm{ml}$ proteinase $\mathrm{K}$ and $1 \%$ Triton X-100 into $1 \times$ PCR buffer, proved to be effective in common PCR. However, when the approach was used in real-time PCR in this study, the high concentration of Triton X-100 in a raw DNA mixture decreased the activity of Taq DNA polymerase (Roche Molecular Biochemicals) and affected the accurate quantification of mtDNA. We changed the protocol and used the ReadyAmp genomic DNA purification resin containing $200 \mu \mathrm{g} / \mathrm{ml}$ proteinase $\mathrm{K}$ as the DNA extraction mixture. Results showed that this is an efficient and simple DNA extraction technique for quantitative PCR analysis of a single embryo. This method not only ensures the complete extraction of mtDNA but also skips a phenol/chloroform extraction step.

\section{The mtDNA copies in NT embryos}

The study of mitochondrial fate in NT embryos is helpful to reveal the mechanism of epigenetic reprogramming. Several reports have shown that there are $1.59 \times 10^{5}$ and 3.14-7.95 $\times 10^{5}$ mtDNAs molecules per mouse and human oocyte (Steuerwald et al. 2000, Barritt et al. 2002) respectively, while there are $2-5 \times 10^{3} \mathrm{mtDNAs}$ in a sheep (Evans et al. 1999) or human (King \& Attardi 1989) somatic cell. The ratio of nuclear donor cell mtDNA to recipient cytoplast mtDNA is about $2-5 \%$ in the reconstructed 1-cell embryos immediately after fusion. Steinborn et al. (2000) quantified the percentage of donor mtDNA in cloned cattle by allele-specific real-time PCR. They observed heteroplasmy in seven of ten cattle clones with the donor-to-recipient ratios ranging from $0.4 \%$ to $4 \%$ and the ratios remained the same throughout development to term, while the other three clones showed a significant reduction or absence of donor mtDNA at ratios $\leq 0.3 \%$. In 
the present study, we estimated the copies of mtDNA in early macaque-rabbit NT embryos at different stages by real-time PCR. A single embryo contains $0.54-2.8 \times 10^{4}$ macaque mtDNAs and $0.13-4.7 \times 10^{7}$ rabbit mtDNAs, values higher than those in early human embryos (King \& Attardi 1989). A previous study found that there was no mtDNA replication until the blastocyst stage in the mouse (Piko \& Taylor 1987). In the present study, we found that the mtDNA copy number in macaque-rabbit cloned embryos from the 1-cell to the morula stage did not change significantly; however, at the blastocyst stage, the mtDNA copies derived from macaque donor cells were reduced and those from recipient rabbit oocytes were significantly increased, suggesting that the maternal mtDNA in the NT embryo replicates after the morula stage. Our results support the conclusion that mtDNA starts replicating at the blastocyst stage. Due to the reduction of donor macaque rabbit mtDNAs and the increase of recipient mtDNAs, the ratio of nuclear donor mtDNA to recipient cytoplast mtDNA also decreased from $2 \%$ at the 1 -cell stage to $0.011 \%$ at the blastocyst stage. Our results suggest that mtDNAs from donor macaque cells and those from enucleated recipient rabbit oocytes coexist in NT embryos from the 1-cell to the blastocyst stage, which is consistent with the result obtained by direct PCR product sequencing (Yang et al. 2003).

\section{Acknowledgements}

We thank Drs Duan-Cheng Wen and Man-Xi Jiang for comments on the manuscript, and Ms Xiang-Fen Song for research assistance. The grant sponsor was The Special Funds for Major State Basic Research Project (001CB5099 and G20000161).

\section{References}

Barritt JA, Kokot M, Cohen J, Steuerwald N \& Brenner CA 2002 Quantification of human ooplasmic mitochondria. Reproductive BioMedicine Online 4 243-247.

Chen DY, Sun QY, Liu JL, Li GP, Lian L, Wang MK, Han ZM, Song XF, Li JS, Sun Q, Chen YC, Zhang YP \& Ding B 1999 The giant panda (Ailuropoda melanoleuca) somatic nucleus can differentiate in rabbit ooplasm and support early development of the reconstructed egg. Science in China (Series C) 29 324-330.

Chen DY, Wen DC, Zhang YP, Sun QY, Han ZM, Liu ZH, Shi P, Li JS, Xiangyu JG, Lian L, Kou ZH, Wu YQ, Chen YC, Wang PY \& Zhang HM 2002 Interspecies implantation and mitochondria fate of panda-rabbit cloned embryos. Biology of Reproduction 67 637642.

Do JT, Hong KH, Lee BY, Kim SB, Kim NH, Lee HT \& Chung KS 2001 In vitro development of reconstructed bovine embryos and fate of donor mitochondria following nuclear injection of cumulus cells. Zygote 9 211-218.

Do JT, Lee JW, Lee BY, Kim SB, Ryoo ZY, Lee HT \& Chung KS 2002 Fate of donor mitochondrial DNA in cloned bovine embryos produced by microinjection of cumulus cells. Biology of Reproduction $67555-560$.

Evans MJ, Gurer C, Loike JD, Wilmut I, Schnieke AE \& Schon EA 1999 Mitochondrial DNA genotypes in nuclear transfer-derived cloned sheep. Nature Genetics 23 90-93.

Giles RE, Blanc H, Cann HM \& Wallace DC 1980 Maternal inheritance of human mitochondrial DNA. PNAS 77 6715-6719.

Han ZM, Chen DY, Li JS, Sun QY, Wang PY, Huang Y \& Du J 2001 The culture of fibroblasts from diaphragm of giant panda. In Vitro Cellular and Developmental Biology 37 644-645.

Hiendleder S, Schmutz SM, Erhardt G, Green RD \& Plante Y 1999 Transmitochondrial differences and varying levels of heteroplasmy in nuclear transfer cloned cattle. Molecular Reproduction and Development 54 24-31.

King MP \& Attardi G 1989 Human cells lacking mtDNA: repopulation with exogenous mitochondria by complementation. Science 246 500-503.

Lanza RP, Cibelli JB, Diaz F, Moraes CT, Farin PW, Farin CE, Hammer CJ, West MD \& Damiani P 2002 Cloning of an endangered species (Bos gaurus) using interspecies nuclear transfer cloning. Cloning 2 79-90.

Loi P, Ptak G, Barboni B, Fulka J, Cappai P \& Clinton M 2001 Genetic rescue of an endangered mammal by cross-species nuclear transfer using post-mortem somatic cells. Nature Biotechnology 19 962-964.

Meirelles FV, Bordignon V, Watanabe $\mathrm{Y}$, Watanabe M, Dayan A Lobo RB, Garcia JM \& Smith LC 2001 Complete replacement of the mitochondrial genotype in a Bos indicus calf reconstructed by nuclear transfer to a Bos taurus oocyte. Genetics 158 351-356.

Piko L \& Taylor KD 1987 Amounts of mitochondrial DNA and abundance of some mitochondrial gene transcripts in early mouse embryos. Developmental Biology 123 364-374.

Smith LC \& Alcivar AA 1993 Cytoplasmic inheritance and its effects on development and performance. Journal of Reproduction and Fertility $\mathbf{4 8}$ (Suppl) 31-43.

Steinborn R, Schinogl P, Zakhartchenko V, Achmann R, Schernthaner W, Stojkovic M, Wolf E, Muller M \& Brem G 2000 Mitochondrial DNA heteroplasmy in cloned cattle produced by fetal and adult cell cloning. Nature Genetics 25 255-257.

Steuerwald N, Barritt JA, Adler R, Malter H, Schimmel T, Cohen J \& Brenner CA 2000 Quantification of mtDNA in single oocytes, polar bodies and subcellular components by real-time rapid cycle fluorescence monitored PCR. Zygote 8 209-215.

Takeda K, Takahashi S, Onishi A, Goto Y, Miyazawa A \& Imai H 1999 Dominant distribution of mitochondrial DNA from recipient oocytes in bovine embryos and offspring after nuclear transfer. Journal of Reproduction and Fertility 116 253-259.

Wan QH, Qian KX \& Fang SGA 2003 A simple DNA extraction and rapid specific identification technique for single cells and early embryos of two breeds of Bos taurus. Animal Reproduction Science 77 1-9.

Yang CX, Han ZM, Wen DC, Sun QY, Zhang KY, Zhang LS, Wu YQ Kou ZH \& Chen DY 2003 In vitro development and mitochondrial fate of macaca-rabbit cloned embryos. Molecular Reproduction and Development 65 396-401.

Received 15 August 2003

First decision 8 October 2003

Accepted 28 October 2003 